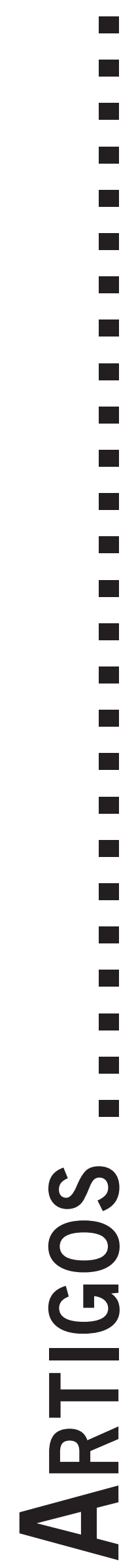




\title{
OS DESAFIOS DA CLÍNICA PSICOLÓGICA: TUTELA E ESCOLHA
}

\author{
The Challenges of the Psychological Practice: Tutelage and Choice
}

Los Retos de la Clínica Psicológica: Tutela y la Elección

Ana Maria Lopez Calvo de Feijoo

Myriam Moreira Protasio

\begin{abstract}
Resumo: Muitos podem ser os referenciais em que se pode fundamentar uma clínica psicológica. Partindo de um diálogo afinado com as filosofias de Kierkegaard e Heidegger, a perspectiva fenomenológico-existencial poderá firmar sua posição de que a clínica consiste em um espaço de conquista de si mesmo. Neste artigo pretendemos colocar em discussão o posicionamento crítico de Kierkegaard a respeito do modo como a ciência, a sabedora de vida e a autoajuda prescrevem aquilo que o homem deve fazer para evitar o tédio, a repetição e o ócio. Em Heidegger, traremos a discussão acerca das tonalidades afetivas da angústia e do tédio, sugerindo que antes de nos distrairmos, de modo a não nos confrontarmos com estes estados de ânimo, é preciso despertar para tais tonalidades, uma vez que são elas que abrem a possibilidade de um rompimento com o horizonte fático sedimentado, o qual nos faz crer que com a ciência, a sabedoria de vida e a autoajuda podemos transformar as contingências de acordo com a soberania da vontade.
\end{abstract}

Palavras-chave: Psicologia Clínica; Fenomenologia; Filosofia da Existência

\begin{abstract}
Many approaches may be used for basis of psychological practice. Stemming from the philosophies of Kierkegaard and Heidegger, the phenomenological-existential perspective can establish its position in the fact that the clinic exists in the realm of self-conquest. Our intention in this article is to examine Kierkegaard's position related to how science, knowledge of life and self-help prescribe what a man should do to avoid boredom, repetitiveness and idleness. In Heidegger, we discuss the affective tonality of anguish and boredom, emphasizing that before we attempt to amuse ourselves, in order to avoid confronting the aforementioned states of mind, it is necessary to be aware of such states, as they open the possibility of a break from the phatic sedentary realm, which leads us to believe that with science, the knowledge of life and self-help we can transform the contingencies according to the sovereignty of will.
\end{abstract}

Keywords: Clinical Psychology; Phenomenology; Philosophy of Existence

Resumen: Muchos pueden ser los puntos de referencia que se puede basar en una clínica psicológica. Desde un diálogo en sintonía con la filosofía de Kierkegaard y Heidegger, la perspectiva existencial-fenomenológico podría reforzar su posición de que la clínica consiste en una conquista del espacio por sí mismo. En este artículo nos proponemos poner en debate la posición crítica de Kierkegaard acerca de la ciencia moderna, la sabiduría de la vida y la autoayuda prescribirem lo que el hombre debe hacer para evitar el tedio y la angustia. En Heidegger traerá la discusión del tono afectivo de la angustia y el tedio, señalando que antes de que se distraiga, por lo que no se enfrentan estos estados de ánimo, hay que despertar a estas tonalidades, al igual que las que se abren posibilidad de una ruptura con el horizonte historico atual, que nos hace creer que con la ciencia, la sabiduría en la vida y la auto-ayuda pueden acudir para contingencias, de conformidad con la soberanía de la voluntad.

Palabras-clave: Psicología Clínica; La Fenomenología; La Filosofía de la Existencia.

\section{Introdução}

A clínica psicológica, pautada na filosofia da existência e no método fenomenológico, pode muito facilmente ser confundida com a filosofia clínica. Aliás, muitas questões surgem quanto à diferença entre essas duas perspectivas. A clínica psicológica também acaba sendo, muitas vezes, confundida com a autoajuda, tanto que, muito frequentemente, aqueles que se encontram no processo clínico perguntam ao psicólogo o que devem fazer frente a questões em que se encontram indecisos. Eles acreditam que os psicólogos conhecem certamente o caminho da decisão inequívoca. Enquanto na filosofia clínica o filósofo assume um posicionamento peda- gógico, que tem como base os ensinamentos da filosofia, na autoajuda aquele que orienta acredita saber como se deve proceder para atingir resultados. Há ainda aqueles que avaliam a clínica psicológica como uma "sabedoria na vida" (Schopenhauer, 1953).

Numa clínica fenomenológico-existencial, nenhum dos posicionamentos expostos acima é tomado como o cerne do processo, que encontra seus fundamentos na fenomenologia e na filosofia da existência. Da fenomenologia, o analista assume a postura antinatural, que consiste em dirigir-se ao fenômeno, sem nenhum pressuposto teórico ou natural, seja da ciência, do senso comum ou da sabedoria de vida. Partindo da filosofia da existência, o analista reconhece o caráter da indeterminação e 
imprevisibilidade do existir, não sendo pertinente, neste sentido, tutelar o outro em suas escolhas, orientar ou indicar caminhos, seja a partir de filosofias, de experiência de vida ou, ainda, de modelos empíricos que ditam verdades a partir do cômputo estatístico ou de sistemas lógicos que pressupõem postulados dos quais se deduzem todas as verdades.

Os filósofos da existência trazem riquíssimas contribuições para que possamos pensar a clínica psicológica, prescindindo dos referenciais de verdade tais como tomados pelos especialistas da ciência, pelas sabedorias de vida ou pela autoajuda. Discussões sobre os diferentes modos de aconselhar, sobre a dicotomização da existência, da angústia, do tédio e do cuidado, dentre outras, serão tratadas aqui a partir dos filósofos Kierkegaard e Heidegger, para então podermos pensar o espaço de realização de uma clínica psicológica que, longe de apontar caminhos, devolve ao homem o cuidado por sua existência, ou seja, a sua própria tutela.

Sören Kierkegaard (1813-1855) elaborou sua filosofia da existência em muitos textos, grande parte deles escritos sob pseudônimos, nos quais tece criticas àqueles que aconselham e tutelam, apontando, algumas vezes, para os perigos que a tutela, o conselho ou a orientação podem trazer, tanto para o aconselhador como para o aconselhando. Destes textos podem ser destacados vários tipos de conselheiros, submetidos aos modos estético, ético ou religioso. Kierkegaard refere-se ao conselheiro estético como aquele que aconselha a partir de sua própria experiência: “deu certo para mim também dará certo para o outro”. O conselheiro estético é aquele que acredita na repetição da experiência, e mais, que pensa que o caráter da repetição é uma prova da validade da verdade estabelecida. O conselheiro ético é aquele que pensa que o conselho deve seguir o caráter da norma, da lei tal como estabelecida pelo universal. Não foi aleatória a escolha feita por este filósofo em usar a pessoa de um juiz como pseudônimo ético. $\mathrm{O}$ conselheiro religioso seria aquele que devolve ao outro a decisão sobre os critérios nos quais pautar as escolhas para a sua vida. Este conselheiro, em uma comunicação indireta, devolve o outro a si mesmo, comportando-se de forma que aquele que lhe pede um conselho possa ouvir a si mesmo e julgar por si mesmo.

Em Heidegger (1889-1976) podemos encontrar uma crítica à tendência a se ditarem caminhos por intermédio de um método que conduza à certeza. Para ele, a verdade como representação está enraizada na dicotomia tradicional entre sujeito e objeto, dicotomia esta que provoca o total esquecimento da existência e a crença de que tudo que diz respeito à fragilidade e vulnerabilidade humanas, inclusive à sua finitude, deveria ser superado. Heidegger apresentou suas teses sempre com o objetivo de retornar à existência e, assim, procedeu à análise do modo de ser do homem, que ele denominou de Dasein. Heidegger abalou a noção tradicional de que a vontade teria soberania e determinaria as escolhas e o destino de cada homem. Ao romper com a dicotomia homem e mundo, a ênfase da existência passou a recair sobre a articulação homem/mundo em uma atmosfera que propicia as vinculações. Logo, não é mais uma subjetividade apartada do mundo que o define e determina. A vontade perde a soberania para a afinação afetiva. Deste modo, caem por terra as autoajudas, as orientações e prescrições dos especialistas e as verdades do senso comum como as sabedorias de vida.

\section{As Temáticas Kierkegaardianas: Comunicação Indireta, Tédio e Repetição}

O tema da obra de Kierkegaard como um todo é o da existência, especificamente o desafio de ser-si-mesmo numa existência que clama por justificar-se, não somente no presente e no contingente, mas sumariamente clama por uma justificativa eterna na existência. Eterno, em Kierkegaard, diz respeito à possibilidade da repetição enquanto uma justificativa que pode se repetir, sempre uma vez mais, pois é uma justificativa eternamente necessária, ou seja, independentemente da situação vivida ela continua sendo minha justificativa. Essa repetição eterna diferencia-se da justificativa no temporal, que se refere às situações vividas contingencialmente e que se justificam apenas em cada situação especifica.

Foi por captar o caráter multifacetado e complexo do existir que o filósofo dinamarquês escreveu utilizando-se de uma metodologia indireta, por meio de pseudônimos e falando através de personagens e de situações vividas por estes, de forma que o leitor pudesse, à medida que lesse cada texto, ver a si mesmo e julgar a si mesmo, exercendo a tarefa excelsa de ser-si-mesmo em meio ao já-estarsendo de algum modo no existir cotidiano. ${ }^{1}$

Muitos que procuram a psicologia clínica queixam-se de depressão. No exercício de uma clínica fenomenológico-existencial o outro nunca se mostra por meio de uma categoria de diagnóstico, mas, diante dele, o clínico assume uma atitude antinatural, que consiste em suspender todos os esclarecimentos prévios, de forma a poder acolher o outro tal qual ele se mostra. Desta forma, inspirados nas reflexões de Kierkegaard sobre o tédio, por exemplo, o clínico assume um posicionamento sem preconceitos, deixando de assumir as referências do senso comum, que tende a compreender o tédio como o enfado da vida cotidiana, o qual provoca, imediatamente, um impulso de repulsão, manifestado ora pela vontade de escapulir dele mediante ocupações, ora pela tendência a se acomodar à "vida pra levar”. Na perspectiva do senso comum, a repetição cotidiana é experimentada como um fardo para o qual não há saída. Nessa situação os conselheiros normalmente oferecem sugestões como entregar-

\footnotetext{
1 As palavras hifenizadas reverenciam aquilo já captado por Heidegger, a impossibilidade de encontrar palavras simples que possam abarcar a complexidade da experiência que está para ser descrita.
} 
se à diversão, aos afazeres, enfim, não parar para pensar, o aconselhamento dando-se no sentido de evitar qualquer pronunciamento desta tonalidade afetiva, tal como denominada por Heidegger.

Serão tomados, aqui, três textos kierkegaardianos, os quais fazem parte de sua grande obra pseudonímica, a partir dos quais se pretende discutir o tema do aconselhamento e de suas consequências. São eles, "Rotação dos cultivos", "O estético e o ético na formação da personalidade" e "A repetição". Os dois primeiros integram a obra Ou...ou. O primeiro pertence ao volume I e foi assinado por um certo "A". O texto seguinte está no volume II da mesma obra e foi assinado pelo Juiz Wilhelm. Esse livro, em seus dois volumes, foi editado por Victor Eremita (Kierkegaard, 2006, 2007). O terceiro texto, cujo título é "A repetição", foi assinado por Constantin Constantius (Kierkegaard, 1976). Todos foram escritos em 1843.

A escolha por falar a partir destes três textos se deve à constatação de que nos três se encontra em discussão uma crítica às relações nas quais as orientações dadas se pautam ou em uma teoria (orientação ética) ou em uma experiência pessoal (orientação estética). Este trabalho pretende recolher algumas destas contribuições e pensar sobre o aconselhar nas temáticas do tédio e da repetição, apontando para o modo como as reflexões deste filósofo podem ser elucidativas para a clínica psicológica e, assim, esclarecer os elementos de uma relação em uma clínica fenomenológico-existencial.

No primeiro destes textos, "Rotação dos cultivos", o autor usa como referência para seus conselhos algo que podemos denominar - plagiando Schopenhauer -, de "Sabedoria na vida", que tem como fundamento a crença de que é possível prescrever procedimentos que, seguidos, garantirão o bem-estar existencial e a ausência do tédio. Nosso autor, o pseudônimo "A", prescreve que se utilize o método da rotação dos cultivos que, inspirado na lógica do homem do campo, tem duas possibilidades: ir mudando de "terreno", ou seja, ir trocando de lugar e, desta forma, iniciar sempre algo novo, ou ir mudando o modo de cultivo, ou seja, controlar o modo como se envolve nas situações de modo a poder exercitar outros modos logo que a situação aponte para um compromisso que ocasionaria o enfado da repetição. Utilizando-se da ironia, tal qual pensada por Kierkegaard em sua tese de doutorado "O conceito de ironia” (1841/1991), e que implica um método de reflexão, uma linguagem que possibilita que aquele que ouve ou que lê possa ver-se refletido e, assim, vendo a si mesmo no texto, refletir sobre sua própria existência, o autor apresenta uma situação que tanto pode ser seguida ao pé da letra, quando se acredita na possibilidade de se escapulir do tédio, como pode servir de alerta para a realidade da vida, à qual pertence tanto o ócio quanto a repetição. Mas estas situações guardam consigo outras possibilidades além do tédio e do enfado, possibilidades que precisam ser experimentadas singularmente e não podem figurar dentro de um manual de sabedoria na vida. Nestes termos o autor, de certa forma, devolve o leitor a si mesmo, para a tarefa de esclarecer seu próprio modo de lidar com o tédio característico da existência.

No outro texto, "O estético e o ético na formação da personalidade”, o autor, Juiz Wilhelm, é, ao que tudo indica, um homem mais velho, casado, e que quer transmitir ao jovem, à guisa de parâmetro comparativo, seu próprio modo de enfrentar a vida cotidiana em seu fluir temporal e em suas determinações. Assume, nessa tarefa, um tom professoral e conselheiro. Ele quer provar ao jovem que o sensual, a beleza e o prazer também têm lugar numa existência que tem seus fundamentos na coragem de assumir compromissos regulares e que prometem longa duração no tempo. Para ele o cotidiano e o habitual não são, necessariamente, um abandono de uma existência leve e movida pela sensualidade, mas sim oportunidade para uma transfiguração do sensual e do singular num plano universal. Para dar voz ao seu apelo escreve uma longa carta ao jovem, dando-lhe todas as diretrizes que certamente o levarão a sair de sua situação para uma bem melhor.

Ao contrário dos conselhos dados pelo jovem, no primeiro texto, os conselhos do Juiz apontam na direção da decisão e do comprometimento, não um comprometimento com uma coisa ou outra, com uma atividade ou outra, mas um compromisso consigo mesmo. O Juiz proclama como maior tesouro a escolha, pois acredita que é justamente $o$ ato de escolher que confere ao homem uma solenidade, uma serena dignidade que jamais se perde completamente, pois no momento da escolha tudo se faz sereno, a alma fica só e o eu recebe a si mesmo. Afirma que a personalidade não é nada antes de haver escolhido a si mesma, pois a grandeza não está em haver escolhido isto ou aquilo, mas em haver escolhido a si mesmo, e todo homem pode se escolher.

Se no texto das "Rotações" o "comprometer-se" aparece como o precursor do tédio, ao trazer a regularidade produtora de enfado para a existência, no segundo texto o que surge é uma possibilidade de ganhar a si mesmo em meio à regularidade de uma vida regida pelo compromisso com as regras. O Juiz insiste na importância da escolha pelo compromisso, que é propriamente o que descreve um posicionamento ético na existência. A vida ética, em sua regularidade, aparece como promessa de felicidade e plenitude, advinda da tranquilidade vivida na repetição. O homem ético descobre o prazer em uma vida sem surpresas, regrada e ritmada pelo hábito, e isso para ele é propriamente ser livre.

É no interior da experiência ética que advém o prazer, na medida em que se descobre o universal da vida. Se para o homem esteta o universal é aquilo que aniquila a vida sensível, para o homem ético é a regularidade e a cadência da vida rotineira que confere um caráter de cerimônia à sequência dos acontecimentos vividos. $\mathrm{O}$ perigo aqui é o da submissão do si mesmo às regras, é o 
perder-se a si mesmo em meio à regularidade pressuposta. O homem ético é aquele que doa tudo ao universal e à regularidade, reconhecendo-se a si mesmo a partir da funcionalidade de sua existência. Tal qual o jovem do texto "Rotação", o Juiz quer desenvolver o método da vida satisfeita consigo mesma, pautada pela submissão à funcionalidade e à utilidade.

Nos dois textos vistos até agora, encontramos os conselhos acerca do tédio pendulando entre a regularidade do universal e a falta de sentido do particular, entre uma vida pautada na busca por novidades e uma vida pautada na regularidade e no comprometimento com as instituiÇões. No texto "A repetição", estes temas retornam, agora concretamente na vida de duas personagens: um velho conselheiro cujo motor é a curiosidade e um jovem apaixonado à procura de conselhos, cujo motor é o agir em conformidade consigo mesmo. O jovem, que gostaria de ser escritor, prometeu casamento a uma jovem, e agora não sabe o que fazer: ama a jovem, mas não quer casar-se, por temor de que a vida regrada do casamento apague o brilho conquistado pelo estado de paixão. Por outro lado, se não cumpre com o compromisso assumido e se entrega à vida poética, a qual alimenta o ofício de escritor, sua vida corre o risco de perder o sentido.

É nesse dilema que o jovem procura um amigo mais velho, com quem desabafa sua situação e perto de quem se sente à vontade para sofrer. O velho entende essa aproximação como um pedido para que faça algo pelo jovem, e este algo é ajudá-lo a sair do impasse. A saída que o conselheiro imagina se dá mediante estratagemas tais que levariam a jovem a romper o compromisso com o rapaz. Tudo vai se articulando de forma a que tal aconteça, o conselheiro tomando todas as providências... Misteriosamente, quando o "jogo" está para começar, o jovem desaparece, deixando o velho sem notícias por um bom tempo, retomando o contato apenas por carta.

Nas cartas, o jovem esclarece que se afastara porque não podia seguir os conselhos do amigo: "Você, amigo meu, possui um poder demoníaco, capaz de tentar qualquer ser humano para que arrisque tudo e se atreva a fazer qualquer coisa" (Kierkegaard, 1843/1976, p. 227). Em outra carta diz: "Não, eu não podia fazer semelhante coisa” (p. 235). Relata, então, seu percurso. Perdido de si mesmo, sem saber que direção tomar, ele tivera contato com o livro bíblico de Jó, onde entendeu que foi só na medida em que ele desistiu de impor as condições para sua vida, em que sacrificou tudo, que conseguiu reaver a si mesmo e à sua vida. $\mathrm{O}$ posicionamento de Jó funciona como um bálsamo para o jovem, que resolve voltar á cidade e cumprir com o prometido. Mas isso não é mais necessário, pois a jovem estava comprometida com outro rapaz, de forma que o jovem recebe, mais uma vez, a possibilidade de se firmar como escritor.

A Repetição (ou retomada, conforme a tradução francesa para a palavra Gjentagelsen), que aparecia inicialmente como um tedioso fluir temporal, surge agora como cons- tituição mesma do existir em sua concretude cotidiana, a qual pressupõe a continuação no tempo. A esperança de felicidade eterna aparecia, inicialmente, como possível a partir da "sabedoria na vida" que tentava estabelecer as condições. Confrontando-se com Jó, a felicidade eterna aparece unindo fé e esforço, imanência e transcendência, universal e singular. Foi preciso coragem para que o jovem saísse da recordação e da esperança e desse um passo no sentido de buscar uma relação séria com o real, seguindo as orientações da própria situação, encontrando, por fim, uma justificativa eterna para a sua existência.

Tudo começa com o não querer ser si mesmo, que transfigura possíveis em necessários, inaugurando uma relação de insatisfação do homem em relação à sua própria realidade. Não se encontrando conciliado com sua própria realidade, os estados de ânimo vão se alterando: ora um desânimo, ora uma agressividade forte, cuja tendência é encontrar responsáveis para tal estado. Kierkegaard sugere outra possibilidade, que acontece a partir de um salto para a monotonia, mas a monotonia criativa. Repetir é retomar, ou seja, é encontrar-se com algo que já se deu, só que de uma forma nova, partindo de medidas na ordem do finito, do temporal ou do universal (o mundo).

Tal qual nos textos apresentados, acreditamos que a relação terapêutica estabelece-se sempre a partir de uma busca de "ajuda” e, na maior parte das vezes, na crença de que o terapeuta é alguém que pode "guiar" o cliente em relação a um "fora dos problemas que o angustiam". Os textos aqui apresentados, em meio à explanação sobre o tédio e a repetição, trazem a figura do conselheiro. Cada um desses conselheiros "conhece", a partir de referenciais próprios, os caminhos a serem seguidos a fim de alcançar uma vida feliz. Um último conselheiro, a figura mítica de Jó, convida a que se pense outra postura possível nessa relação entre conselheiro e aconselhado. Quando o jovem procurou o amigo conselheiro o que recebeu foi uma saída pragmática para uma situação que ele ainda estava aprendendo a conhecer. O que o jovem encontra na história de Jó é a si mesmo, no sentido de que encontra a justificativa de seu existir. O desafio da terapia de inspiração kierkegaardiana é, então, poder abrir um espaço em que seja possível esse "instante transformador", tal qual pensado pelo filósofo em seu texto "Migalhas filosóficas" (1844/1995), onde aquele que procura "ajuda" possa ouvir a si mesmo em relação às possibilidades universais que ele mesmo é.

\section{As Temáticas Heideggerianas: Angústia e Tédio}

Heidegger não tinha a preocupação, a princípio, de, através de sua fenomenologia hermenêutica, viabilizar uma clínica psicológica. Mas psiquiatras e psicólogos viram em suas obras elementos para elaborar uma clínica que rompesse com as determinações subjetivistas, baseadas no domínio da representação, da vontade e dos sen- 
timentos. Assim, a clínica inspirada em Heidegger declinaria das crenças de que há uma verdade representativa passível de ser alcançada por um método reto e seguro; de que a vontade é soberana sob a máxima de que poder é querer e de que os sentimentos, apenas, é que dão colorido à verdade e à vontade.

Os psiquiatras e psicoterapeutas Ludwig Binswanger e Medard Boss, em um diálogo afinado com Heidegger, procedem a uma clínica psicológica, à qual denominaram Daseinsanálise, que irá se afastar de qualquer tentativa de ditar caminhos a seguir por aquele que busca fazer escolhas, libertar-se da angústia ou do tédio, em um processo de análise.

A Daseinsanálise, portanto, consiste em uma clínica psicológica que não mapeia, não conduz, não conscientiza, enfim, em que o analista não tutela as escolhas do analisando, mas antes liberta o outro para que ele mesmo escolha a sua existência e assuma a tutela pela sua própria vida. $\mathrm{O}$ daseinsanalista mantém-se como guardião do espaço em que o analisando possa reconhecer-se no seu caráter de vulnerabilidade e indeterminação; logo, reconhece que seu mundo não se constituirá consoante a sua vontade, independentemente de qualquer método que venha a utilizar. E o reconhecimento de sua condição existencial não acontece por meio da distração com relação às tonalidades afetivas fundamentais, angústia e tédio, mas, justamente, permitindo a afinação com estas tonalidades. Heidegger, ao questionar-se sobre como devemos abrir espaço para a angústia e o tédio, inicialmente inessenciais e inapreensíveis, ele mesmo reponde que basta não ficarmos contra tais tonalidades, mas nos aproximarmos delas e deixarmos que elas nos digam o que querem, afinal. Trata-se, justamente, da postura que o analista, em um diálogo clínico, deve tomar frente à inquietação daquele que, na angústia e no tédio, o procura.

Em “Ser y tiempo” (Heidegger, 1989), a angústia foi tematizada como a tonalidade afetiva capaz de promover o instante do acontecimento apropriação, na medida em que esta disposição afetiva tende a quebrar o caráter cristalizado de todas as coisas, revelando, assim, o caráter de poder-ser do ser-aí. Já em "Os conceitos fundamentais da metafísica” (2006), encontramos o tédio profundo como tonalidade afetiva.

Tédio e angústia constituem-se como tonalidades afetivas fundamentais que viabilizam a crise do projeto do impessoal, abrindo espaço para que a singularização se dê. Enquanto na angústia há um repetido esvaziamento do sentido que sustenta o movimento existencial cotidiano e tudo, então, se mostra como possibilidade, no tédio todo o campo temporal desaparece, o ser-aí não temporaliza mais e o nada se mostra, na total ausência de possíveis. Tanto a angústia como o tédio, enquanto disposições afetivas fundamentais, têm em comum o caráter de situação limite e o fato de abrirem a possibilidade de trazer à tona o mundo como espaço de singularização do ser-aí, bem como o espaço de diferenciação entre o ser-aí e os outros.
A angústia deve ser compreendida, então, como uma das tonalidades afetivas fundamentais que, ao descerrar mundo, rompendo com as sedimentações do mundo fático, lança o horizonte de sentido em uma insignificância radical. Deste modo, tudo cai em uma total indiferença e em um radical esvaziamento. E é nesta situação limite, com o romper das prescrições do mundo, que pode ocorrer um despertar para o espaço de realização do ser-aí, ou seja, que se abre o seu poder-ser. A angústia, ao apontar para a negatividade originária da existência, coloca em jogo a compreensão da finitude, que abre o caráter de nada da existência, do ente ontologicamente incompleto e indeterminado, desvelando o poder do mundo sobre nós.

A angústia constitui-se, então, em tonalidade afetiva fundamental do estar-aí em fuga de si mesmo e que se dá frente ao nada e indeterminado da existência, tonalidade na qual todas as prescrições do mundo são suspensas. Com a total ruptura da estrutura de significados, abre-se a possibilidade de apresentar-se o caráter de poder-ser, colocando o Dasein frente a frente às suas possibilidades de escolher-se a si mesmo. A angústia, como disposição do Dasein, vai abrir a possibilidade de compreensão de si mesmo a partir do mundo, ainda que lançado, a princípio numa interpretação pública. Na angústia, ocorre a confrontação com o nada da existência, abrindo a possibilidade da suspensão do poder prescritivo do discurso do mundo, ou seja, a suspensão radical da significância como expressão do mundo fático. Quando isto acontece, o ser-aí se vê confrontado com o seu poder-ser, emergindo daí duas possibilidades: retomar o ritmo da existência impessoal ou rearticular o projeto existencial a partir do poder-ser singular que o ser-aí sempre é.

Tédio, que na palavra alemã Langeweile quer dizer tempo longo, aponta na descrição heideggeriana para o momento que se alonga e do qual comumente queremos nos ver livres por meio dos passatempos. Portanto, ele se refere a um modo de nos colocarmos diante do tempo, no qual o presente, o passado e o futuro encontram uma modulação particular. Heidegger descreve três formas de tédio: "ser entediado por algo" - tédio que pode ser abafado, na medida em que matamos o tempo e, assim, não escutamos sua origem propriamente dita; "o entediar-se" - situação intermediária, na qual o tédio se transforma em princípio operativo de nosso existir, desencadeando de antemão estruturas de passatempo voltadas a impedir que ele venha à tona; "tédio profundo" - no qual somos obrigados a ouvi-lo.

Na tonalidade afetiva do tédio, o ser-aí se depara com uma recusa de todas as coisas, como fechamento das possibilidades de realização do mundo. $\mathrm{O}$ tédio traz à tona o mundo como espaço de singularização do ser-aí, bem como espaço de diferenciação entre o ser-aí e os outros, e consiste no traço determinante do mundo atual, no qual o homem se tornou desinteressante para si mesmo. Este homem absorvido pela técnica, desarticulado da rela- 
ção com sua historicidade, inviabiliza a conquista de si próprio. O tédio profundo, tonalidade afetiva que nasce do fato de nos confrontarmos radicalmente com o desinteresse por tudo, e no final das contas por nós mesmos, portanto, não é algo externo. Ele não chega para nós de fora, mas, vindo do fundo de nossa própria negatividade, nos aprisiona em um mundo no qual o tempo desaparece. É a finitude do tempo, em que a existência não rearticula mais o passado com o presente e o futuro desaparece. Sem a possibilidade do temporalizar há uma eternização do instante, no qual nenhum instante é possível e o horizonte se nega para o ser-aí. Ao preenchermos o momento, o tédio, tonalidade afetiva que denuncia a totalidade inabarcável que nos assalta e nos afunda, não aparece. E, nesse horizonte dessa lenta demora, o vazio aparece e desiste-se. Em Heidegger, o tédio profundo mobiliza duas situações: um despertar para um sentido e, ao mesmo tempo, a tentativa de não deixar que desperte. Segundo Heidegger(2006, p.233): "No tédio, propicia-se o inabarcado apelo do ser". Na tonalidade afetiva fundamental do tédio transparece o que há de mais próprio ao ser-aí, o ser-para-a-morte. Na disposição do tédio acede sempre a transparência da situação do homem, que em última instância é finita e transitória.

A finitude do ser-aí aparece plenamente no ser-paraa-morte. Na relação da finitude com o cuidado, aquela se constitui no traço marcante do horizonte de realização do cuidado que o ser-aí tem de ser. Ela (a finitude) chega ao ser-aí como horizonte de realização do poder-ser. Trata-se da relação originária com o ser-aí como indeterminação, ou seja, da relação que parte do ser-aí na determinação imediata de sua existência. O caráter de poderser do ser-aí se mostra o constantemente estar em jogo com o seu ser, que sempre resiste a uma apreensão total; e ainda, por sua característica de abertura, sempre não concluído, jamais alcança uma totalidade, permanecendo sempre inconcluso.

Em conclusão, o conselho, as orientações a partir da sabedoria de vida e as orientações de autoajuda apontam para a necessidade da tutela daquele que sabe, orienta e ensina como autoajudar-se, tal como proposto em um horizonte cientificista ou do senso comum, nos quais reina o ideal de verdade, vontade, transparência e método. Romper com essa tutela é fundamental para, assim, lançar os fundamentos de uma clínica fenomenológicoexistencial, com base na Fenomenologia e na Filosofia da Existência.

No início de nosso texto mencionamos a questão de uma possível confusão entre uma psicologia clínica e uma filosofia clínica, dúvida de muitos que, interessados nas possíveis convergências e divergências entre estas duas posturas, se perguntam: Seria a mesma temática? Teriam o mesmo objetivo? Trata-se apenas de uma duplicação? São âmbitos diferentes de atuação? Como ficaria então a diferenciação entre a psicologia clínica com bases fenomenológico-existenciais e a filosofia clínica?
A filosofia clínica oferece àqueles que procuram o filósofo um saber cognitivo sobre o que diz as filosofias acerca daquilo que está em questão para este que procura o filósofo. Trata-se de um conhecer filosófico. Já na atuação psicológica, não temos nenhuma preocupação em teorizar acerca dos conceitos ou elaborações filosóficos. Estes apenas propiciam elementos para que o psicólogo clínico existencial possa romper com as verdades da ciência psicológica acerca do psiquismo, do autorreconhecimento, entre outras. Na clínica psicológica, consideramos que o espaço terapêutico pode ser articulado a partir da abertura de um espaço contingente no qual o analisando possa ver a si mesmo, julgar-se por si mesmo, encontrando a medida eterna de sua existência.

\section{Referências}

Heidegger, M. (1989). Ser y tiempo. Madrid: Editorial Gredos.

Heidegger, M. (2006). Os conceitos fundamentais da metafísica. São Paulo: Forense-Universitária.

Kierkegaard, S.A. (1976). In vino veritas e La repetición. Madrid: Ediciones Guadarrama (Original publicado em 1843).

Kierkegaard, S.A. (1991). O conceito de ironia, constantemente referido a Sócrates. Petrópolis: Vozes. (Original publicado em 1841).

Kierkegaard, S.A. (1995). Migalhas filosóficas ou um bocadinho de filosofia de João Clímacus. Petrópolis: Vozes. (Original em 1844).

Kierkegaard, S.A. (2006). O lo uno o lo otro: un fragmento de vida. Vol.I. Madrid: Editorial Trotta.

Kierkegaard, S.A. (2007). O lo uno o lo otro: un fragmento de vida. Vol. II. Madrid: Editorial Trotta.

Schopenhauer, A. (1953). Aforismos para a sabedoria na vida. São Paulo: Edições Melhoramentos.

Ana Maria Lopez Calvo de Feijoo - Doutora em Psicologia, ProfessorAdjunto da Graduação e do Programa de Pós-Graduação em Psicologia Social da Universidade do Estado do Rio de Janeiro. Endereço Institucional: Universidade do Estado do Rio de Janeiro, Departamento de Psicologia Clínica, Instituto de Psicologia. Rua São Francisco Xavier, 524 (Maracanã). CEP: 20550.013. Rio de Janeiro, RJ. Email: ana.maria.feijoo@gmail.com.br

Myriam Moreira Protasio - Possui graduação em Psicologia pela Faculdade de Humanidades Pedro II e Especialização em Psicologia Clínica pelo IFEN - Instituto de Psicologia Fenomenológico-Existencial do Rio de Janeiro. É Doutoranda em Filosofia no Programa de PósGraduação em Filosofia da Universidade do Estado do Rio de Janeiro. Email:myprotasio@yahoo.com.br

Recebido em 12.10 .10 Aceito em 21.12.10 